\title{
Hemidactylus frenatus (Squamata: Gekkonidae): call frequency, movement and condition of tail in Costa Rica
}

\author{
Caty Frenkel ${ }^{1}$ \\ 1 Tarqui 19-26 y E. Espejo, Cuenca, Ecuador; caty_frenkel@yahoo.com
}

Received 10-VIII-2004. Corrected 06-II-2006. Accepted 09-VIII-2006.

\begin{abstract}
Call frequency and movements of the gecko Hemidactylus frenatus were studied in Punta Morales, Costa Rica from April 1999 through May 2000. Call activity of H. frenatus was positively related to air temperature at night and throughout the year. Higher activity was at dusk, dawn, and during the hottest months. Call frequency was related with gecko abundance per month, although not during the night. More males and females had a regenerated tail compared to juveniles, the last ones could have it complete or regenerated. Females moved longer distances than males and juveniles. Adults were found higher on walls. Males and females were recaptured more times than juveniles, and the period of time between their recaptures was longer. Members of this population do not seem to be as aggressive to other geckos as mentioned in the literature. Rev. Biol. Trop. 54 (4): 1125-1130. Epub 2006 Dec. 15.
\end{abstract}

Key words: call frequency, gecko distribution, Hemidactylus frenatus, autotomy, temperature, seasonality.

Hemidactylus frenatus (Schlegel, 1836) is one of the 70 species of this genus. It has a world wide distribution (Church and ChunSim 1961, Hunsaker II 1966, Bustard 1970, Synder and Weathers 1976, Cheng and Lin 1977, 1978, Frankenberg 1982) and is reported in the new continent in Mexico, Panama and some places of the United States (Marcellini 1970, McCoy and Busack 1970, Poulin et al. 1995). In Costa Rica this species has been reported but there are no studies about its natural history or activity.

As mentioned somewhere else (Marcellini 1970), this nocturnal gecko is mostly associated to human edifications and is often found near artificial lights. For this and other species of geckos daily and seasonal activity have been studied, including data of number of individuals, call frequency, and movement range of captive animals. In $H$. frenatus the activity range varies daily and annually both in tropical and temperate areas (Bustard 1970, Marcellini 1971, 1974, Frankenberg and Werner 1981), probably being correlated to luminosity, temperature, rain, and human activity (Marcellini 1970).

Several authors mention that $H$. frenatus is aggressive (Hunsaker II 1966, Marcellini 1970, McCoy and Busack 1970, Bolger and Case 1992, Petren et al. 1993, Case et al. 1994), and fights or encounters may result in persecutions, tail loss or scars resulting from bites (Marcellini 1970, Bolger and Case 1992). Besides its autotomic characteristic, the tail has an important role in the natural history of this species. Males and females use the tail during courtship, as part of an advertisement signal to other geckos, and when they localize a prey (Marcellini 1970).

Some authors mention that $H$. frenatus is territorial and has a social hierarchy, aspects closely related to movement and distribution of the individuals. Dominant adults can determine the distribution of young or other species of geckos that cohabit the same area (Hunsaker II 1966, Marcellini 1970, Lin and Cheng 1984, McCoid and Hensley 1993, Hanley et 
al. 1998). This distribution and displacement of animals can be related to animal density, aggressiveness, dominance or tolerance among each other (Marcellini 1970).

Because there is no study that analyzes these characteristics of the natural history and ecology of $H$. frenatus in Costa Rica, and the aspects related to tail loss and movement range still need to be understood, the purpose of this study was to determine the period of higher calling activity during the night and along the year on a population of $H$. frenatus in Costa Rica, and if this is related to air temperature and animal abundance; determine the tail condition by sex and size of the animals; and finally analyze some aspects related to the displacement on the building where this population inhabit.

\section{MATERIALS AND METHODS}

The study was done in the Universidad Nacional Field Station in Punta Morales, Costa Rica. Call frequency at night was measured counting the number of calls during the first 15 min of each hour. Simultaneously, air and surface temperature (building wall) were also measured. Calling activity and number of individuals were related by counting the number of individuals immediately after measuring surface temperature. Geckos were captured and data were recorded: sex, snout-vent length (SVL), tail length (from the cloaca to the distal part of the tail), and tail condition as complete (a tail that had not been cut or regenerated) or regenerated (it had been cut or had a regeneration scar), in three different points: the base, in the middle or in the tip. Each gecko was marked by cutting phalanx. For each gecko observation (captures and recaptures), the exact place in the building where the gecko was found was logged. The position was measured as the horizontal distance from one extreme of the wall to the place were the gecko was, and the vertical distance from the base of the wall to the height on the gecko. The movement between two capture points was calculated as the minimum linear distance the gecko could have moved using the walls.

\section{RESULTS}

Daily patterns for air and surface temperature were very similar, having a higher peak at dusk and dawn $(\mathrm{F}=42.730, \mathrm{p}<0.001, \mathrm{df}=13.210$; Fig. 1). These peaks coincided with the ones for gecko calling activity $(\mathrm{F}=13.748, \mathrm{p}<0.001$, $\mathrm{df}=$ 13.143; Fig. 1). Calling production was seasonally related to air temperature, when the mean temperature was higher geckos called more often $(F=4.991, p=0.027, d f=1.143$; Fig. 2). Air and surface temperatures were lower in February 2000, followed by higher temperature in March, April, and May ( $\mathrm{F}=32.673, \mathrm{p}<0.001$, $\mathrm{df}=$ 12.210; Fig. 2). Calling activity was low in April, but increased in May of both years. In September and December 1999 it rained, the temperatures were lower, and there was a decrease in calling activity (Fig. 2).

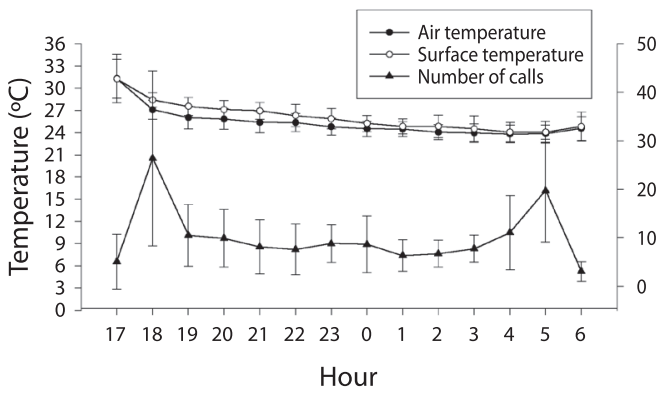

Fig. 1. Air temperature, surface temperature and number of calls of $H$. frenatus (average and standard deviation) per hour.

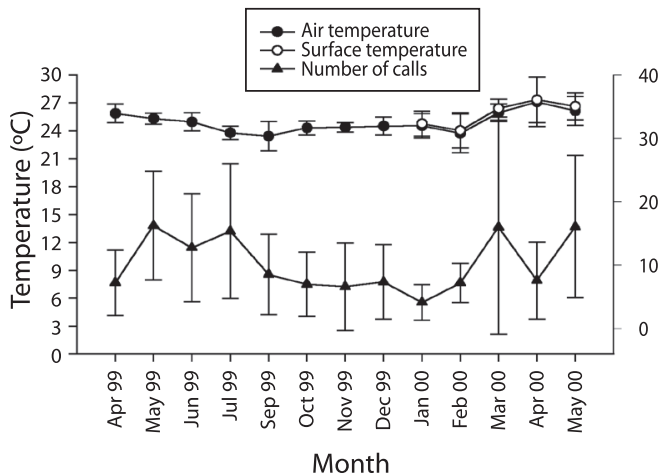

Fig. 2. Air temperature, surface temperature and number of calls of $H$. frenatus (average and standard deviation) per month. 
Considering gecko abundance in relation to calling production (general linear model, Lindsey 1999), both factors were positive related $(\mathrm{t}=7.960, \mathrm{p}<0.001, \mathrm{df}=1)$. Geckos called more at dusk than at midnight $(\mathrm{t}=-7.330$, $\mathrm{p}<0.001, \mathrm{df}=1$ ). Months with higher number of geckos had higher calling activity. Numbers of calls were higher in March $(\mathrm{t}=4.380, \mathrm{p}<0.001$, $\mathrm{df}=3)$ and May $(\mathrm{t}=3.360, \mathrm{p}<0.001, \mathrm{df}=3)$, and also the number of geckos for both months (March: $\mathrm{t}=2.460, \mathrm{p}=0.014, \mathrm{df}=3$; May: $\mathrm{t}=$ $2.800, \mathrm{p}=0.005, \mathrm{df}=3$ ). Gecko abundance was not different between dusk and midnight $(\mathrm{t}=$ $-1.700, p=0.089, \mathrm{df}=1)$, but it varied between months. It was lower in April and February ( $\mathrm{t}=$ $1.410, \mathrm{p}=0.160, \mathrm{df}=3$ ). The decrease of calling activity seen at midnight was not related to a decrease in gecko abundance. April had more geckos at midnight (contrary to February, March, and May) and fewer calls. However, the decrease in calls per month was related to low gecko abundance.

Having a regenerated tail was more common in adults $(83 \%$ of males and $69 \%$ of females) than in juveniles (45\%) $\left(X^{2}=33.312\right.$, $\mathrm{p}<0.001, \mathrm{df}=2)$. More males had a tail regenerated at the base than males with a complete tail. $\left(X^{2}=8.765, \mathrm{p}=0.033, \mathrm{df}=3\right)$. Females could have it complete or regenerated at any point $\left(X^{2}\right.$ $=5.405, \mathrm{p}=0.144, \mathrm{df}=3$ ), and juveniles with complete tails were more common than juveniles with a tail regenerated at any point $\left(X^{2}=\right.$ 43.380, $\mathrm{p}<0.001, \mathrm{df}=3$; Table 1). If we include the factor of gecko size, individuals of different sizes had different conditions $(\mathrm{F}=3.544, \mathrm{p}=$ $0.002, \mathrm{df}=6.339$; Table 1). Males with the tail regenerated in the middle had a higher average size than males with complete tails (LSD, $\mathrm{p}<0.001)$. Females of any size could have complete or regenerated tails at any point (LSD, $\mathrm{p}<0.05$ ). Juveniles with the tail regenerated in the base had a larger average length than the ones with complete tails (LSD, $\mathrm{p}<0.001$ ).

In the building, the distance geckos moved varied per sex $(\mathrm{F}=4.481, \mathrm{p}=0.014, \mathrm{df}=2.77$; Table 2). Females moved farther than males (LSD, $\mathrm{p}=0.019)$ and than juveniles (LSD, $\mathrm{p}=$ 0.017 ), but the last two moved similar distances (LSD, $\mathrm{p}<0.05$ ). Although females moved longer distances than males and juveniles (Table 2), adults of both sexes and also juveniles have been captured close to each other.

The height where geckos were located also varied per sex $(\mathrm{F}=9.873, \mathrm{p}<0.001, \mathrm{df}=2.154$; Table 2). Juveniles were at lower heights than males (LSD, $p=0.001$ ) and females

TABLE 1

Percentage and size (SVL, mean \pm S.D.) of males, females and juveniles of $\mathrm{H}$. frenatus with complete tails (C), regenerated in the tip (RT), in the middle (RM) and in the base (RB)

\begin{tabular}{lcccccccc} 
& \multicolumn{3}{c}{$\%$ Geckos } & \multicolumn{5}{c}{ Gecko size (cm) } \\
& C & RT & RM & RB & C & RT & RM & RB \\
Males & 16.8 & 29.4 & 20.2 & 33.6 & $5.17 \pm 0.61$ & $5.56 \pm 0.41$ & $5.67 \pm 0.44$ & $5.45 \pm 0.52$ \\
Females & 30.7 & 17.6 & 25.5 & 26.1 & $4.78 \pm 0.39$ & $4.84 \pm 0.4$ & $4.91 \pm 0.36$ & $4.8 \pm 0.47$ \\
Juveniles & 55.7 & 22.8 & 7.6 & 13.9 & $2.41 \pm 0.52$ & $2.73 \pm 0.52$ & $2.66 \pm 0.5$ & $3.2 \pm 0.59$
\end{tabular}

TABLE 2

Movement, height perch and captures time of males, females and juveniles of $\mathrm{H}$. frenatus

\begin{tabular}{lcccccc} 
& \multicolumn{2}{c}{ Males } & \multicolumn{3}{c}{ Females } & \multicolumn{2}{c}{ Juveniles } \\
Displacement between recaptures & $6.3 \pm 6.2$ & $\mathrm{~N}=27$ & $8.3 \pm 9.3$ & $\mathrm{~N}=37$ & $2.8 \pm 2.9$ & $\mathrm{~N}=12$ \\
Height between recaptures (m) & $2.3 \pm 0.9$ & $\mathrm{~N}=27$ & $2.5 \pm 0.9$ & $\mathrm{~N}=37$ & $1.8 \pm 1.1$ & $\mathrm{~N}=12$ \\
Days between recaptures & $29.6 \pm 25.4$ & $\mathrm{~N}=55$ & $34.4 \pm 29.4$ & $\mathrm{~N}=76$ & $18.5 \pm 12.8$ & $\mathrm{~N}=22$
\end{tabular}


(LSD, $\mathrm{p}<0.001$ ), but adults of both sexes were at similar heights (LSD, $\mathrm{p}=0.624$ ).

The distances geckos displaced among recaptures were not correlated to the time between captures in males $(\mathrm{r}=0.006, \mathrm{p}=0.963, \mathrm{~N}=55)$, females $(\mathrm{r}=-0.03, \mathrm{p}=0.775, \mathrm{~N}=76)$ or juveniles $(\mathrm{r}=0.330, \mathrm{p}=0.134, \mathrm{~N}=22)$. Otherwise, the time between recaptures did vary per sex $(\mathrm{F}=3.168$, $\mathrm{p}=0.040, \mathrm{df}=2.150$; Table 2 ). It was longer in females than in juveniles (LSD, $p=0.013$ ), but did not defer between males and females (LSD, $\mathrm{p}=0.302$ ). It tended to be higher in males than in juveniles (LSD, $\mathrm{p}=0.096$ ).

\section{DISCUSSION}

The relation between temperature and gecko activity (Fig. 1), represented as a higher temperature and higher activity at dusk and dawn, also occurs in other species of geckos, for example Thecadactylus, Gehyra, Ptenopus, and Hemidactylus turcicus (Frankenberg 1982). Seasonally, months with higher temperatures had more geckos and higher calling activity, pattern also found by Marcellini (1970). It is suggested that the temperature during the day could determine the degree of gecko activity at night, where higher temperatures during the day are related to higher activity at night. Gecko shelters have high temperatures during the day, which can increase gecko body temperature and accelerate digestion process, causing more animals to forage at night (Marcellini 1970).

Although temperature and number of calls is related, another factor, such as gecko abundance, is also involved to calling activity of this species. The relationship between abundance and calling activity could explain why in April the number of geckos and calls were low although temperature was high (Fig. 2).

The higher percentage of adults compared to juveniles having the tail regenerated at any point (Table 1) is also common in other species. In H. garnotii and H. turcicus, $54 \%$ and $65 \%$ of adults, respectively, had tails in regeneration, compared with $10 \%$ and $31 \%$ in juveniles (Marcellini 1970). It is not known the reason for tail breakage at the base, the middle, or the tip. Greer (1989) says that tail loss in geckonids is mainly at the base (the first five non autotomic vertebrae are followed by vertebrae that are autotomic), although it can also be broken at different parts. Tail loss can occur because of fights between individuals or predator attacks. This loss allows the survival of the gecko at the cost of losing the tail (Marcellini 1970, Greer 1989).

It is possible that males are not as aggressive as mentioned in previous literature, because they would move farther apart or to another building to avoid contact with the aggressive males, (a same gecko was never captured in a different building), and as a consequence there would be males that could disappear during the study, but it did not happen. The movement of males reported by Marcellini (1970) is similar to those found here, but females in this study seam to move farther away. Brattstrom (1974) and Wilson (1975) say that an increase in density could produce an increase of aggressive interactions between animals. Although there are persecutions and aggressions between individuals (Marcellini 1970, pers. obs.), there is a possibility that this species has a social hierarchy system.

Marcellini (1970) also found that males and females remain in higher places, and that higher locations have better thermoregulation properties and provide more shelter for rain and wind. The temperature is also a little bit higher and because the presence of artificial lights, insects are more abundant. Because juveniles remained in lower places, they could not have much contact with adults. The occurrence of fights between adults and juveniles were therefore reduced, lowering instances of tail loss in juveniles. Adults also eat juveniles of the same species (Bolger and Case 1992, pers. obs., McCoid and Hensley 1993), therefore, being in lower places can avoid cannibalism. Fights between juveniles had not been reported in literature and in this study was not observed. This could also explain the lower tail regeneration proportion in juveniles as compared to adults.

Geckos do not necessarily move longer distances apart when the time passed is longer 
(Table 2), suggesting that they remain within certain ranges. Males and females had longer periods of time without being re-observed (Table 2), probably because they remained in places with difficult access, as the roof. Because juveniles were in lower parts of the building, it was possible that they did not move to the roof, where adults could stay for a certain period, reason to have a longer time between adult recaptures. It has been reported that $H$. frenatus is aggressive with individuals of the same species and others (Church and Chun-Sim 1961, Hunsaker II 1966, Marcellini 1970, McCoy and Busack 1970, Bolger and Case 1992, Petren et al. 1993, Case et al. 1994, Schmidt et al. 1996), and that is dominant over other species that live in the same habitat, sometimes forcing them to re-locate (such as $H$. garnotii, Lepidodactylus lugubris and Leiolopisma metallica). They pursue and bite other geckos, eat their young, and prevent other species from reaching the refuges and feeding places. Marcellini (1970), Bolger and Case (1992), and Case et al. (1994) say that within the species, males tolerate other individuals of the same sex less, but they tolerate females and juveniles, while females tolerate individuals of both sexes and juveniles.

\section{ACKNOWLEDGMENTS}

I specially thank F. Bolaños and W. Eberhard for their assistance and guidance during the research, R. Acuña for his useful knowledge and M. Sasa and L.D. Gómez for their comments and corrections. I also thank the staff from the National University station in Punta Morales, Puntarenas and the Organization for Tropical Studies for financial support.

\section{RESUMEN}

Estudié la frecuencia de canto y el desplazamiento de la lagartija Hemidactylus frenatus en Punta Morales, Costa Rica. La frecuencia de canto se corelaciona positivamente con la temperatura ambiental durante la noche y con la temperatura a lo largo del año. La mayor actividad fue al anochecer, al amanecer y durante los meses más calurosos. La abundancia mensual de lagartijas se relacionó con la frecuencia de canto, no así la abundancia por noche. Las colas regeneradas son más frecuentes en hembras y machos que en las lagartijas jóvenes. Las hembras se desplazaron mayores distancias que machos y jóvenes. Los adultos se encontraban más alto en las paredes de los edificios. Los machos y hembras se recapturaron más veces que los jóvenes, y el tiempo entre recapturas fue mayor. Esta población no parece ser tan agresiva como se menciona en la literatura.

Palabras clave: frecuencia de canto, distribución, temperatura, estacionalidad, Hemidactylus frenatus, autotomía.

\section{REFERENCES}

Bolger, D.T. \& T.J. Case. 1992. Intra and interspecific behaviour among sexual and asexual geckos. Anim. Behav. 44: 21-30.

Brattstrom, B. 1974. The evolution of reptilian social behavior. Amer. Zool. 14: 35-49.

Bustard, H.R. 1970. Activity cycle of the tropical house gecko Hemidactylus frenatus. Copeia 1970: 173-176.

Case, T.J., D.T. Bolger \& K. Petren. 1994. Invasions and competitive displacement among house geckos in the tropical Pacific. Ecology 75: 464-477.

Cheng, H.Y. \& J.I. Lin. 1977. Comparative reproductive biology of the lizards Japalura swinhonis formosensis, Takydromus septentrionalis and Hemidactylus frenatus in Taiwan. I. Male reproductive cycles. Bull. Inst. Zool. Acad. Sinica 17: 107-121.

Cheng, H.Y. \& J.I. Lin . 1978. Comparative reproductive biology of the lizards Japalura swinhonis formosensis, Takydromusseptentrionalis and Hemidactylus frenatus in Taiwan. II. Fat body and liver cycles in males. Bull. Inst. Zool. Acad. Sinica 17: 67-74.

Church, G. \& L. Chun-Sim. 1961. The distribution of three species of house gecko in Bandung (Java). Herpetologica 17: 199-201.

Frankenberg, E. 1982. Vocal behavior of the mediterranean house gecko, Hemidactylus turcicus. Copeia 1982: 770-775.

Frankenberg, E. \& Y.L.Werner. 1981. Adaptability of the daily activity pattern to changes in longitude, in a colonizing lizard, Hemidactylus frenatus. J. Herp. 15: 373-376.

Greer, A.E. 1989. The biology \& evolution of australian lizards. Surrey Beaty,Sidney, Australia. 264p. 
Hanley, K.A., K. Petren \& T.J. Case. 1998. An experimental investigation of the competitive displacement of a native gecko by an invading gecko: no role of parasites. Oecologia 115: 196-205.

Hunsaker II, D. 1966. Notes on the population expansion of the house gecko, Hemidactylus frenatus. Phillip. J. Sc. 95: 121-122.

Lin, J. \& H. Cheng. 1984. Ovarian cycle in the house gecko, Hemidactylus frenatus in Taiwan with reference to food stress in winter. Bull. Inst. Zool., Acad. Sicina 23: 21-28.

Lindsey, J.K. 1999. Applying generalised linear models. Springer, Berlin, Germany. 257 p.

Marcellini, D.L. 1970. Ethoecology of Hemidactylus frenatus (Sauria, Gekkonidae) with emphasis on acoustic behavior. PhD. Dissertation, University of Oklahoma, Oklahoma, USA. 200 p.

Marcellini, D.L. 1971. Activity patterns of the gecko Hemidactylus frenatus. Copeia 1971: 631-635.

Marcellini, D.L. 1974. Acoustic behavior of the gekkonid lizard, Hemidactylus frenatus. Herpetologica 30: 44-52.
McCoid, M.J. \& R.A. Hensley. 1993. Shifts in activity patterns in lizards. Herp. Rev. 24: 87-88.

McCoy, C.J. \& S.D. Busack. 1970. The lizards Hemidactylus frenatus and Leiolopisma metallica on the island of Hawaii. Herpetologica 26: 303.

Petren, K.D.T. Bolger \& T.J. Case. 1993. Mechanisms in the competitive succes of an invading sexual gecko over as asexual native. Science 259: 354-358.

Poulin, B., G. Lefevbre \& A.S. Rand. 1995. Hemidactylus frenatus (house gecko): foraging. Herp. Review 26: 205.

Schmidt, W.F. Mendoza \& M.E. Martínez. 1996. Range extensions for Hemidactylus frenatus in Mexico. Herp. Rev. 27: 30.

Synder, G.K. \& W.W. Weathers. 1976. Physiological responses to temperature in the tropical lizard, Hemidactylus frenatus (Sauria: Gekkonidae). Herpetologica 32: 252-257.

Wilson, O.E. 1975. Sociobiology: The new synthesis. Belkap, Harvard University, Massachussetts, USA. $697 \mathrm{p}$. 